\title{
A novel gene expression system for Ralstonia eutropha based on the T7 promoter
}

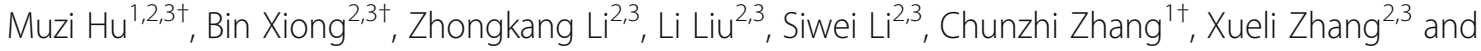 \\ Changhao $\mathrm{Bi}^{2,3^{*}}$
}

\begin{abstract}
Background: Ralstonia eutropha (syn. Cupriavidus necator) is a model microorganism for studying metabolism of polyhydroxyalkanoates (PHAs) and a potential chassis for protein expression due to various advantages. Although current plasmid systems of $R$. eutropha provide a basic platform for gene expression, the performance of the expression-inducing systems is still limited. In addition, the sizes of the cloned genes are limited due to the large sizes of the plasmid backbones.

Results: In this study, an R. eutropha T7 expression system was established by integrating a T7 RNA polymerase gene driven by the $P_{B A D}$ promoter into the genome of $R$. eutropha, as well as adding a T7 promoter into a pBBR1derived plasmid for gene expression. In addition, the essential DNA sequence necessary for pBBR1 plasmid replication was identified, and the redundant parts were deleted reducing the expression plasmid size to $3392 \mathrm{bp}$, which improved the electroporation efficiency about 4 times. As a result, the highest expression level of RFP was enhanced, and the L-arabinose concentration for expression induction was decreased 20 times.
\end{abstract}

Conclusions: The R. eutropha T7 expression system provides an efficient platform for protein production and synthetic biology applications.

Keywords: Ralstonia eutropha, Cupriavidus necator, T7 expression system, pBBR1 plasmid, Protein expression system

\section{Background}

Ralstonia eutropha, also known as Cupriavidus necator, is a facultative chemolithoautotrophic bacterium which is able to fix $\mathrm{CO}_{2}$ via the Calvin-Benson-Bassham (CBB) cycle [1]. It is a model microorganism for studying the metabolism of polyhydroxyalkanoates (PHAs) [1, 2]. When phosphorus or nitrogen was limited, the weight of poly(3-hydroxybutyrate) (PHB) accumulated in the cells

\footnotetext{
*Correspondence: bi_ch@tib.cas.cn

${ }^{\dagger}$ Muzi Hu, Bin Xiong and Chunzhi Zhang contributed equally to this work. ${ }^{2}$ Tianjin Institute of Industrial Biotechnology, Chinese Academy of Sciences, Tianjin 300308, People's Republic of China

${ }^{3}$ Key Laboratory of Systems Microbial Biotechnology, Chinese Academy of Sciences, Tianjin 300308, People's Republic of China

Full list of author information is available at the end of the article
}

exceeded $80 \%$ of the cell dry weight [3], which makes $R$. eutropha a potential industrial strain for PHA production.

Metabolic engineering and synthetic biology were used to engineer $R$. eutropha for the production of biofuels and other valued-added products, such as isobutanol [4], 3-methyl-1-butanol [4], methyl ketones [5], hydrocarbons [6], ethanol [7], isopropanol [8, 9], fatty acids [10] and $\alpha$-humulene [11]. $R$. eutropha is also a potential chassis for production of industrial enzymes and proteins due to its ability to suppress the formation of inclusion bodies [12], lack of acidic byproducts, and high fermentation cell density [3]. When the enzyme organophosphohydrolase $(\mathrm{OPH})$ was produced in engineered $R$. eutropha, its content reached more than $10 \mathrm{~g} / \mathrm{L}$, which

(c) The Author(s). 2020 Open Access This article is licensed under a Creative Commons Attribution 4.0 International License, which permits use, sharing, adaptation, distribution and reproduction in any medium or format, as long as you give appropriate credit to the original author(s) and the source, provide a link to the Creative Commons licence, and indicate if changes were made. The images or other third party material in this article are included in the article's Creative Commons licence, unless indicated otherwise in a credit line to the material. If material is not included in the article's Creative Commons licence and your intended use is not permitted by statutory regulation or exceeds the permitted use, you will need to obtain permission directly from the copyright holder. To view a copy of this licence, visit http://creativecommons.org/licenses/by/4.0/ The Creative Commons Public Domain Dedication waiver (http://creativecommons.org/publicdomain/zero/1.0/) applies to the data made available in this article, unless otherwise stated in a credit line to the data. 
was a more than 100 -fold increase compared to $\mathrm{OPH}$ expression in E. coli [12]. This indicated that $R$. eutropha is a potential industrial protein production host.

A robust gene expression toolbox which includes suitable host strains, plasmid vectors and promoters is essential for metabolic engineering and synthetic biology. Plasmids derived from $\mathrm{pBBR} 1$, and from plasmids of.

IncP and IncQ can replicate in $R$. eutropha individually or compatibly and were used as its plasmid vectors [6]. Promoters used in E. coli, such as $\mathrm{P}_{\mathrm{lac}}$ and $\mathrm{P}_{\mathrm{tac}}$ [13], were found to be expressed constitutively in $R$. eutropha, while native promoters from $R$. eutropha, such as $\mathrm{P}_{\text {phaC }}$ [14], $P_{\text {phaP }}$ [14], $P_{\text {phb }}$ [14], $P_{\text {acoE }}$ [14], $P_{\text {acoD }}$ [14] and $\mathrm{P}_{\text {pdhe }}[14]$, were also evaluated to be functional $[13,14]$. In addition, promoters induced by L-arabinose [6], Lrhamnose [15], and anhydrotetracycline [16] were used in $R$. eutropha. However, most of the plasmid vectors and promoters mentioned above are not frequently used. Although broad-host-range plasmid vectors derived from pBBR1 with the L-arabinose induced promoter $\mathrm{P}_{\mathrm{BAD}}$ are currently the most popular ones, the vectors are very large, which limits the sizes of carried genes and decreases plasmid transformation efficiency.

In this study, a gene expression system based on the T7 promoter was constructed to improve the current gene expression technology for $R$. eutropha and make it a better protein expression system.

\section{Results}

\section{Construction of a T7 gene expression system for $R$. eutropha}

The T7 RNA polymerase gene was cloned from E. coli BL21(DE3), modified to be driven by the L-arabinose induced promoter $\mathrm{P}_{\mathrm{BAD}}$, and the $r f p$ gene was cloned under the control of a T7 promoter (taatacgactcactataggg). The resulting plasmid pj5_00019, based on pBBR1, was introduced into either E. coli S17-1 [17] or $R$. eutropha C5 ( $R$. eutropha H16 $\Delta H 16 \_A 0006 \Delta H 16$ A0008-9) [18]. However, we found that $r f p$ was expressed in E. coli S17-1, but was not expressed in $R$. eutropha $\mathrm{C} 5$ with or without L-arabinose induction. We considered that the failure of expression in $R$. eutropha might due to the multiple copies of the T7 RNA polymerase genes expressed from the multicopy plasmid.

To verify the hypothesis, $R$. eutropha strain C5T7 was constructed by integrating the RNA polymerase gene with the $\mathrm{P}_{\mathrm{BAD}}$ promoter and araC into the H16_A0666 locus on the R. eutropha C5 genome. H16_A0666 is annotated as lactate dehydrogenase of $R$. eutropha. Because $R$. eutropha strictly depends on respiratory chain for metabolism, the function of lactate dehydrogenase seems redundant. Therefore, we speculate that the removal of H16_A0666 may not affect its growth, which was verified by the experimental results. The expression plasmid
pBBR1- $\mathrm{P}_{\mathrm{T} 7}-\mathrm{rfp}$ was constructed by cloning the T7promoter-driven $r f p$ into the pBBR1 backbone. After electroporation into $R$. eutropha C5T7, the strain C5T7(pBBR1- $\mathrm{P}_{\mathrm{T} 7}-\mathrm{rfp}$ ) showed visible red color when induced (Fig. 1), which indicated a T7 gene expression system for R. eutropha was successfully constructed.

\section{Minimization of the expression plasmid vector $\mathrm{PBBR} 1-\mathrm{P}_{\mathrm{T}^{-}}$ rfp}

The pBBR1- $\mathrm{P}_{\mathrm{T} 7}$-rfp plasmid expressed in $R$. eutropha C5T7 had a size of $4751 \mathrm{bp}$, which limited the size of genes that can be cloned into the vector. Considering the origin of the plasmid, there might be redundant DNA regions that are non-essential for plasmid replication and could be deleted to minimize the plasmid. The DNA cassette containing acttaaaaatcaacaacttaaaaa is AT-

\section{a R. eutropha $\mathrm{C5}$}

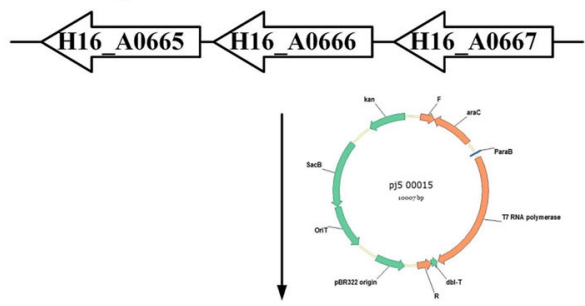

R. eutropha C5T7
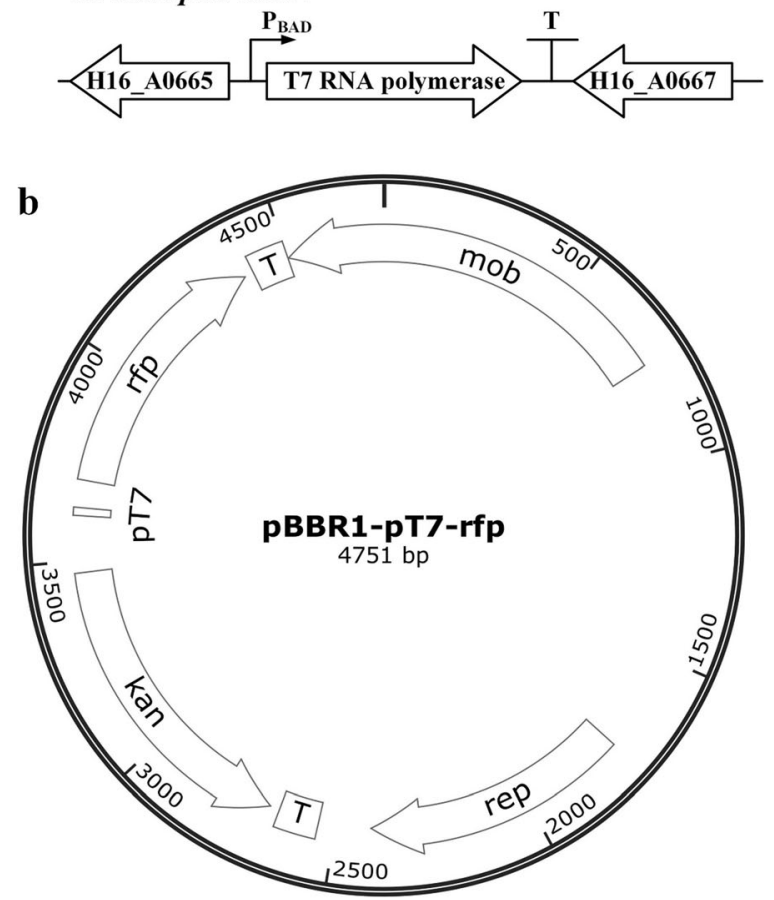

Fig. 1 Schematic of the R. eutropha gene expression system. The system includes engineered $R$. eutropha C5T7 (a) and plasmid vector (b). a Schematic illustration of the gene arrangment of changed genomic locus of $R$. eutropha C5T7. b Profile of gene expression vector pBBR1-PT7-Ifp. Bacterial colonies are visually red when $R$. eutropha C5T7(pBBR1-PT7-rfp) is induced by arabinose 
rich with two direct repeats, which was assumed to be the replication origin of pBBR1-derived plasmids [19]. Thus, adjacent regions of the putative replication origin were gradually deleted via PCR followed by Golden Gate assembly to reassemble the plasmids. As a result, a series of circular DNA cassettes were constructed, among which only pj5_00030 could be introduced into E. coli successfully, which confirmed that only this plasmid contained a functional minimized origin of replication (Fig. 2a). The putative replication origin with about 400 bp of its upstream sequence was conserved in pj5_00030 and was essential for plasmid replication. The minimized plasmid vector pj5_00030 was designated as pBBR1-P $\mathrm{T}_{7}-$ rfp(mini) (Fig. 2b, Additional file 2).

\section{Gene expression efficiency of the $R$. eutropha T7 expression system}

To determine the performance of the R. eutropha T7 expression system with the minimized expression plasmid, pBBR1- $\mathrm{P}_{\mathrm{T} 7}-\mathrm{rfp}(\mathrm{mini})$ was transferred into $R$. eutropha C5T7 via electroporation for expression analysis. Rfp expression was induced by different concentrations of L-

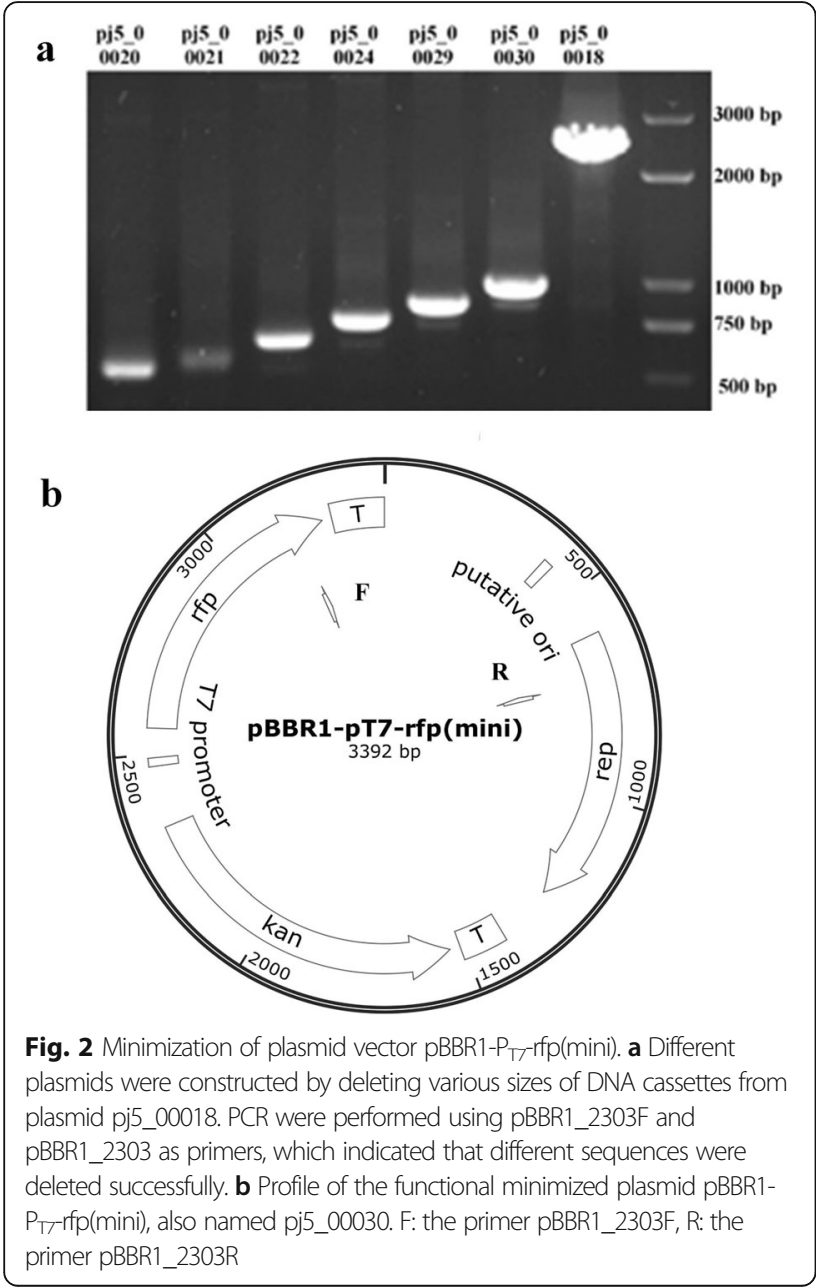

arabinose. The results showed that the expression level of Rfp increased with the increase of L-arabinose concentration in the range from 0 to $0.1 \mathrm{mg} / \mathrm{mL} \mathrm{L}$-arabinose. When $0.1 \mathrm{mg} / \mathrm{mL}$-arabinose was added for induction, the expression level of RFP was highest but decreased when L-arabinose exceeded that threshold (Fig. 3a). Compared with pBBR1-P $\mathrm{BAD}-\mathrm{rfp}$ in $R$. eutropha H16, the highest RFP expression level of $R$. eutropha C5T7(pBBR1- $\mathrm{P}_{\mathrm{T} 7}-\mathrm{rfp}(\mathrm{mini})$ ) was improved. Especially, due to the higher sensitivity of the T7 expression system, the L-arabinose concentration needed for the highest induction level was lowered 20X compared with the traditional $\mathrm{P}_{\mathrm{BAD}}$ system (Fig. 3a), which can bring significant cost savings in industry.

\section{Electroporation efficiency of the plasmid}

To evaluate the electroporation efficiency of the pBBR1derived plasmids, $\mathrm{pBBR} 1-\mathrm{P}_{\mathrm{BAD}}-\mathrm{rfp}, \mathrm{pBBR} 1-\mathrm{P}_{\mathrm{T} 7}-\mathrm{rfp}$ and

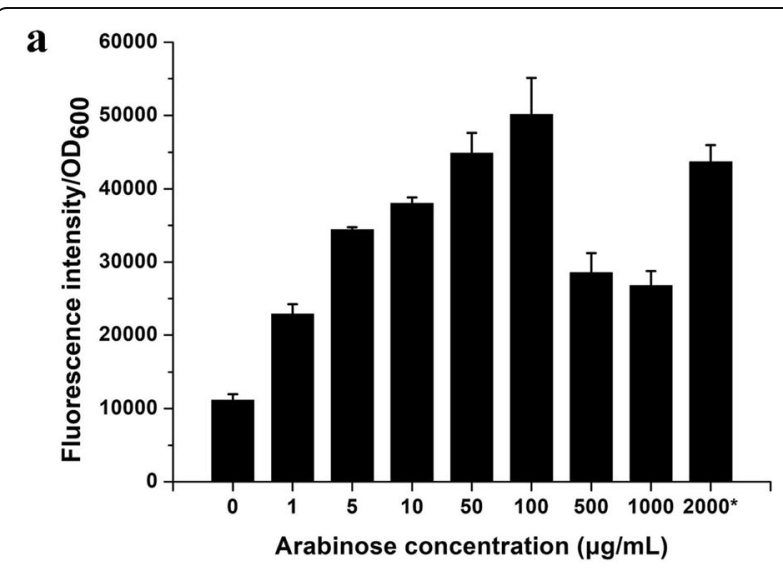

b

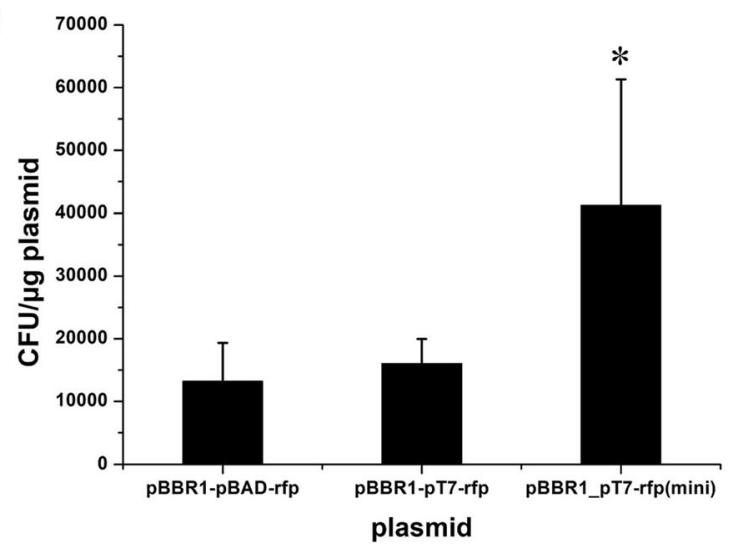

Fig. 3 The induced expression strength and electroporation efficiency of pBBR1-P $\mathrm{P}_{\mathrm{T}-\mathrm{rfp}} \mathrm{\text {mini}}$ ). a Red fluorescent intensity of $R$. eutropha C5T7(pBBR1-P $\mathrm{P}_{\mathrm{T}-\mathrm{rfp}}$ (mini)) with induction of different concentrations of L-arabinose. 2000*: RFP intensity of $R$. eutropha $\mathrm{H} 16$ (pBBR1-P $\left.{ }_{\mathrm{BAD}}-\mathrm{rfp}\right)$ with $2000 \mu \mathrm{g} / \mathrm{mL}$ L-arabinose. $\mathbf{b}$ electroporation efficiency of PBBR1$P_{B A D}-r f p, p B B R 1-P_{T 7}-r f p$ and pBBR1-P $P_{T 7}-r f p$ (mini) into C5T7 strain. The results represent three biological replicates. The difference was significant $(P<0.05)$ 
pBBR1-P ${ }_{\mathrm{T} 7}-\mathrm{rfp}$ (mini) were extracted from E. coli $\mathrm{S} 17-1$, and then individually electroporated into $R$. eutropha C5T7 competent cells. The results showed that the electroporation efficiency of pBBR1- $\mathrm{P}_{\mathrm{T} 7}-\mathrm{rfp}(\mathrm{mini})$ was significantly higher than that of $\mathrm{pBBR} 1-\mathrm{P}_{\mathrm{BAD}}-\mathrm{rfp}$ or pBBR1-P $\mathrm{T}_{\mathrm{T} 7 \mathrm{rfp}}$, probably due to the reduced plasmid size (Fig. 3b). Thus, the minimized vector could provide a better cloning efficiency.

\section{Discussion}

T7 expression system for $R$. eutropha was constructed in this work. This system provides an alternative other than current systems, such as Escherichia coli and Bacillus subtilis, which also bring some improvements over current systems. The major advantages probably include $R$. eutropha's ability to suppress the formation of inclusion bodies [12], lack of acidic byproducts, and high fermentation cell density [3]. In addition, since the presence of antibiotics resistance form the plasmid was stable during the all the culturing and experiment process, we considered the expression system was relatively stable.

\section{Conclusions}

In this study, an optimized T7 expression system for $R$. eutropha was constructed for protein expression, synthetic biology manipulation and other applications. The system has a few advantages over previous ones. First, with the high sensitivity of the T7 system, the highest expression level was enhanced, and the L-arabinose concentration for induction was decreased 20 times, offering great cost saving. Secondly, due to the minimized size of the expression vector, the electroporation efficiency was improved 4 times $(p<0.05)$, which also makes the plasmid a better vector for accommodating large DNA cassettes.

\section{Methods}

\section{Strains and culture conditions}

The strains used in this study are listed in Table S1. E. coli was cultured at $37^{\circ} \mathrm{C}$ in lysogeny broth medium (LB, $10 \mathrm{~g} / \mathrm{L}$ peptone, $5 \mathrm{~g} / \mathrm{L}$ yeast extract, $10 \mathrm{~g} / \mathrm{L} \mathrm{NaCl}$ ). Streptomycin $(100 \mu \mathrm{g} / \mathrm{mL})$ or kanamycin $(50 \mu \mathrm{g} / \mathrm{mL})$ was added to the medium where appropriate. $R$. eutropha was cultured in LB at $30^{\circ} \mathrm{C}$. Gentamycin $(10 \mu \mathrm{g} / \mathrm{mL})$ or kanamycin $(200 \mu \mathrm{g} / \mathrm{mL})$ was added where appropriate.

\section{Primers and plasmids}

Primers (Table S2) used for the construction of plasmids (Table S3) in this study were designed using j5 Device Editor [20]. The other primers were designed using Clonemanager software. High fidelity DNA polymerase was purchased from Takara (Dalian, China) or New England Biolabs (USA). BsaI restriction endonuclease and T4 ligase were purchased from New England Biolabs (USA) and Thermo-Fisher Scientific (USA), respectively. Plasmids were constructed using Golden Gate [21], Gibson [22] or CPEC [23] methods, and used to transform $E$. coli or $R$. eutropha. Plasmids were extracted using the AxyPrep Plasmid Miniprep Kit (AXYGEN, China) according to the manufacturer's instructions, with minor modifications.

\section{Genome integration of $R$. eutropha}

Integration of araC and T7 RNA polymerase genes into $R$. eutropha C5 ( $R$. eutropha H16 $\Delta H 16 \_A 0006 \Delta H 16$ A0008-9) [18] was performed with the pk18mobsacb suicide plasmid with similar procedure as our previous work [18]. For construction of the integration plasmid pj5_00015, the DNA cassettes of left homologous arm, AraC gene, PBAD promoter, T7 RNA polymerase gene and terminator were assembled into pk18mobsacb plasmid with the Golden gate method. Plasmid pj5_00015 was then transferred into $R$. eutropha C5 strain by bacterial transconjugation. And the strain with kanamycin resistance was screened on agar plates containing $200 \mu \mathrm{g} / \mathrm{ml}$ kanamycin. The strain with genomic integrated pj5_00015 was selected by colony PCR. To eliminate the DNA cassette containing antibiotic marker, the above selected strain was cultured in $\mathrm{NaCl}$ free $\mathrm{LB}$ liquid media containing $10 \%$ sucrose, and then plated agar plate containing the same content to screen for strain with no kanamycin Integration of araC and T7 RNA polymerase genes into $R$. eutropha C5 ( $R$. eutropha H16 $\left.\Delta H 16 \_A 0006 \Delta H 16 \_A 0008-9\right)$ [18] was performed with the pk18mobsacb suicide plasmid with similar procedure as our previous work [18]. For construction of the integration plasmid pj5_00015, the DNA cassettes of left homologous arm, AraC gene, PBAD promoter, T7 RNA polymerase gene and terminator were assembled into pk18mobsacb plasmid with the Golden gate method. Plasmid pj5_00015 was then transferred into $R$. eutropha C5 strain by bacterial transconjugation. And the strain with kanamycin resistance was screened on agar plates containing $200 \mu \mathrm{g} / \mathrm{ml}$ kanamycin. The strain with genomic integrated pj5_00015 was selected by colony PCR. To eliminate the DNA cassette containing antibiotic marker, the above selected strain was cultured in $\mathrm{NaCl}$ free $\mathrm{LB}$ liquid media containing $10 \%$ sucrose, and then plated agar plate containing the same content to screen for strain with no kanamycin resistance. The obtained strain was confirmed again with colony PCR and sequencing of the PCR products, which was designated as $R$. eutropha C5T7 strain.

Integration of araC and T7 RNA polymerase genes into $R$. eutropha C5 (R. eutropha H16 $\Delta H_{16}$ A0006 $\left.\Delta H 16 \_A 0008-9\right)$ [18] was performed with the pk18mobsacb suicide plasmid with similar procedure as 
our previous work [18]. For construction of the integration plasmid pj5_00015, the DNA cassettes of left homologous arm, AraC gene, PBAD promoter, T7 RNA polymerase gene and terminator were assembled into pk18mobsacb plasmid with the Golden gate method. Plasmid pj5_00015 was then transferred into R. eutropha C5 strain by bacterial transconjugation. And the strain with kanamycin resistance was screened on agar plates containing $200 \mu \mathrm{g} / \mathrm{ml}$ kanamycin. The strain with genomic integrated pj5_00015 was selected by colony PCR. To eliminate the DNA cassette containing antibiotic marker, The above selected strain was cultured in $\mathrm{NaCl}$ free LB liquid media containing 10\% sucrose, and then plated agar plate containing the same content to screen for strain with no kanamycin resistance. The obtained strain was confirmed again with colony PCR and sequencing of the PCR products, which was designated as R. eutropha C5T7 strain.

Integration of araC and T7 RNA polymerase genes into $R$. eutropha C5 (R. eutropha H16 $\Delta H 16$ $\left.A 0006 \Delta H 16 \_A 0008-9\right)$ [18] was performed with the pk18mobsacb suicide plasmid with similar procedure as our previous work [18]. For construction of the integration plasmid pj5_00015, the DNA cassettes of left homologous arm, AraC gene, PBAD promoter, T7 RNA polymerase gene and terminator were assembled into pk18mobsacb plasmid with the Golden gate method. Plasmid pj5_00015 was then transferred into $R$. eutropha C5 strain by bacterial transconjugation. And the strain with kanamycin resistance was screened on agar plates containing $200 \mu \mathrm{g} / \mathrm{ml}$ kanamycin. The strain with genomic integrated pj5_00015 was selected by colony PCR. To eliminate the DNA cassette containing antibiotic marker, The above selected strain was cultured in $\mathrm{NaCl}$ free $\mathrm{LB}$ liquid media containing $10 \%$ sucrose, and then plated agar plate containing the same content to screen for strain with no kanamycin resistance. The obtained strain was confirmed again with colony PCR and sequencing of the PCR products, which was designated as $R$. eutropha C5T7 strain.

Integration of araC and T7 RNA polymerase genes into $R$. eutropha C5 (R. eutropha H16 H16 A0006 $\left.4 H 16 \_A 0008-9\right)$ [18] was performed with the pk18mobsacb suicide plasmid with similar procedure as our previous work [18]. For construction of the integration plasmid pj5_00015, the DNA cassettes of left homologous arm, AraC gene, PBAD promoter, T7 RNA polymerase gene and terminator were assembled into pk18mobsacb plasmid with the Golden gate method. Plasmid pj5_00015 was then transferred into $R$. eutropha C5 strain by bacterial transconjugation. And the strain with kanamycin resistance was screened on agar plates containing $200 \mu \mathrm{g} / \mathrm{ml}$ kanamycin. The strain with genomic integrated pj5 00015 was selected by colony PCR. To eliminate the DNA cassette containing antibiotic marker, The above selected strain was cultured in $\mathrm{NaCl}$ free $\mathrm{LB}$ liquid media containing 10\% sucrose, and then plated agar plate containing the same content to screen for strain with no kanamycin resistance. The obtained strain was confirmed again with colony PCR and sequencing of the PCR products, which was designated as $R$. eutropha C5T7 strain.

Integration of araC and T7 RNA polymerase genes into $R$. eutropha C5 (R. eutropha H16 $\Delta H 16_{-}$ A0006 $\left.\Delta H 16 \_A 0008-9\right)$ [18] was performed with the pk18mobsacb suicide plasmid with similar procedure as our previous work [18]. For construction of the integration plasmid pj5_00015, the DNA cassettes of left homologous arm, AraC gene, PBAD promoter, T7 RNA polymerase gene and terminator were assembled into pk18mobsacb plasmid with the Golden gate method. Plasmid pj5_00015 was then transferred into R. eutropha C5 strain by bacterial transconjugation. And the strain with kanamycin resistance was screened on agar plates containing $200 \mu \mathrm{g} / \mathrm{ml}$ kanamycin. The strain with genomic integrated pj5_00015 was selected by colony PCR. To eliminate the DNA cassette containing antibiotic marker, The above selected strain was cultured in $\mathrm{NaCl}$ free LB liquid media containing $10 \%$ sucrose, and then plated agar plate containing the same content to screen for strain with no kanamycin resistance. The obtained strain was confirmed again with colony PCR and sequencing of the PCR products, which was designated as $R$. eutropha C5T7 strain.

Integration of araC and T7 RNA polymerase genes into $R$. eutropha C5 (R. eutropha H16 H16 A0006 $\left.4 H 16 \_A 0008-9\right)$ [18] was performed with the pk18mobsacb suicide plasmid with similar procedure as our previous work [18]. For construction of the integration plasmid pj5_00015, the DNA cassettes of left homologous arm, AraC gene, PBAD promoter, T7 RNA polymerase gene and terminator were assembled into pk18mobsacb plasmid with the Golden gate method. Plasmid pj5_00015 was then transferred into R. eutropha C5 strain by bacterial transconjugation. And the strain with kanamycin resistance was screened on agar plates containing $200 \mu \mathrm{g} / \mathrm{ml}$ kanamycin. The strain with genomic integrated pj5_00015 was selected by colony PCR. To eliminate the DNA cassette containing antibiotic marker, The above selected strain was cultured in $\mathrm{NaCl}$ free LB liquid media containing 10\% sucrose, and then plated agar plate containing the same content to screen for strain with no kanamycin resistance. The obtained strain was confirmed again with colony PCR and sequencing of the PCR products, which was designated as R. eutropha C5T7 strain. 


\section{Assessment of RFP expression levels}

Red fluorescence intensity was measured using a microplate reader (Infinite M200 PRO, TECAN) after the strains were induced with L-arabinose for $48 \mathrm{~h}$. The excitation and emission wavelengths were 585 and $620 \mathrm{~nm}$ respectively [6]. Optical density at $600 \mathrm{~nm}\left(\mathrm{OD}_{600}\right)$ was also measured using the microplate reader. The RFP expression levels were determined as the ratio of the red fluorescence intensity to the $\mathrm{OD}_{600}$.

\section{Identification of the region necessary for plasmid replication}

Different primers for Golden Gate were designed using j5 DeviceEditor, and PCR was implemented using the plasmid pBBR1- $\mathrm{P}_{\mathrm{T} 7}-\mathrm{rfp}$ as template. The products of the PCR were purified using the SanPrep DNA Purification Kit (Sangon Biotech, China), and then cyclized via Golden Gate assembly. As a result, some regions of the pBBR1- $\mathrm{P}_{\mathrm{T} 7}$-rfp were deleted, and the minimized plasmids were used to transform E. coli. Transformed colonies would be obtained if the core region for plasmid replication was intact, while transformation would be unsuccessful if the core region were damaged.

\section{Electroporation of $R$. eutropha and evaluation of transformation efficiency}

Competent cells of $R$. eutropha were prepared according to the protocol described in our previous work [18]. Briefly, $R$. eutropha was cultured in $100 \mathrm{~mL} \mathrm{LB}$ at $30{ }^{\circ} \mathrm{C}$ and $200 \mathrm{rpm}$, then chilled on ice for 5-10 min after the $\mathrm{OD}_{600}$ reached 0.8 . The cells were collected by centrifugation at $3000 \times \mathrm{g}$ for $5 \mathrm{~min}$ and washed with ice-cold sterile $10 \%(\mathrm{~V} / \mathrm{V})$ glycerol three times. Finally, the cells were suspended in about $0.5 \mathrm{~mL} 10 \%$ glycerol and 0.1 $\mathrm{mL}$ portions transferred to sterile $1.5-\mathrm{mL}$ tubes. The prepared $R$. eutropha competent cells were used immediately, or frozen in liquid nitrogen and preserved at $80{ }^{\circ} \mathrm{C}$ for a few weeks.

Electroporation of $R$. eutropha was implemented according to the protocol described in our previous work [18]. Briefly, appropriate plasmids were added to the competent cells and mixed gently. The mixture was transferred into a pre-chilled 2-mm electroporation $\mathrm{cu}$ vette (Bio-Rad, USA), and incubated on ice for $5 \mathrm{~min}$, after which electroporation was performed at a voltage of $2.3 \mathrm{kV}$. Immediately afterwards, $1 \mathrm{~mL}$ of LB preincubated at $30{ }^{\circ} \mathrm{C}$ was added to the cells. All the cells were transferred to a sterile $1.5 \mathrm{~mL}$ tube and incubated at $30{ }^{\circ} \mathrm{C}$ for $2 \mathrm{~h}$. Then, a portion of the cells was spread on LB agar plates with appropriate antibiotics, and cultured at $30^{\circ} \mathrm{C}$ until colonies were visible. Electroporation efficiencies were calculated as the ratio of colony-forming units (CFU) to the amount of the used plasmid DNA.

\section{Supplementary information}

Supplementary information accompanies this paper at https://doi.org/10. 1186/s12866-020-01812-9.

Additional file 1. Table S1, Table S2 and Table S3.

Additional file 2. Sequence of $\mathrm{pBBR} 1-\mathrm{P}_{\mathrm{T} 7}$-rfp (mini).

Abbreviations

R.eutropha: Ralstonia eutropha; PHAs: Polyhydroxyalkanoates; CBB: CalvinBenson-Bassham; PHB: Poly(3-hydroxybutyrate);

$\mathrm{OPH}$ : Organophosphohydrolase; CFU: Colony-forming units

\section{Acknowledgements}

Not Applicable.

Authors' contributions

$H M, X B, L Z, L L$ and $L S$ planned and performed the experiments, analyzed and interpreted the data. ZC, BC and ZX supervised the study, designed the experiments and analyzed and interpreted the results. XB and HM wrote the manuscript. All authors read and approved the final manuscript.

\section{Funding}

Fund supporting this research was mainly supported by the Key Research Program of the Chinese Academy of Science (KFZD-SW-215, ZDRW-ZS-20163), and minorly supported by National Natural Science Foundation of China (31522002, 31770105).

The funder have no role in conducting this research.

\section{Availability of data and materials}

We provide supporting and necessary data for publication of the article. All supporting data is present in the article and the supplemental material documents. The sequences of the constructed vectors were in Additional file 2 .

Ethics approval and consent to participate Not applicable.

Consent for publication

Not applicable.

\section{Competing interests}

The authors declare that they have no competing interests.

\section{Author details}

${ }^{1}$ School of Biological Engineering, Dalian Polytechnic University, Dalian 116034, People's Republic of China. ${ }^{2}$ Tianjin Institute of Industrial Biotechnology, Chinese Academy of Sciences, Tianjin 300308, People's Republic of China. ${ }^{3}$ Key Laboratory of Systems Microbial Biotechnology, Chinese Academy of Sciences, Tianjin 300308, People's Republic of China.

Received: 15 January 2020 Accepted: 5 May 2020

Published online: 19 May 2020

\section{References}

1. Pohlmann A, Fricke WF, Reinecke F, Kusian B, Liesegang $H$, Cramm R, Eitinger T, Ewering C, Pötter M, Schwartz E. Genome sequence of the bioplastic-producing "Knallgas" bacterium Ralstonia eutropha H16. Nat Biotechnol. 2006;24:1257-62.

2. Reinecke F, Steinbüchel A. Ralstonia eutropha strain H16 as model organism for PHA metabolism and for biotechnological production of technically interesting biopolymers. J Mol Microbiol Biotechnol. 2009;16:91-108.

3. Ryu HW, Hahn SK, Chang YK, Chang HN. Production of poly(3hydroxybutyrate) by high cell density fed-batch culture of Alcaligenes eutrophus with phosphate limitation. Biotechnol Bioeng. 1997:55:28-32.

4. Li H, Opgenorth PH, Wernick DG, Rogers S, Wu T-Y, Higashide W, Malati P, Huo Y-X, Cho KM, Liao JC. Integrated electromicrobial conversion of $\mathrm{CO}_{2}$ to higher alcohols. Science. 2012;335:1596.

5. Müller J, MacEachran D, Burd H, Sathitsuksanoh N, Bi C, Yeh Y-C, Lee TS, Hillson NJ, Chhabra SR, Singer SW, Beller HR. Engineering of Ralstonia 
eutropha $\mathrm{H} 16$ for autotrophic and heterotrophic production of methyl ketones. Appl Environ Microbiol. 2013;79:4433-9.

6. Bi C, Su P, Müller J, Yeh Y-C, Chhabra SR, Beller HR, Singer SW, Hillson NJ. Development of a broad-host synthetic biology toolbox for Ralstonia eutropha and its application to engineering hydrocarbon biofuel production. Microb Cell Factories. 2013;12:107.

7. Lee HM, Jeon BY, Oh MK. Microbial production of ethanol from acetate by engineered Ralstonia eutropha. Biotechnol Bioprocess Eng. 2016;21:402-7.

8. Grousseau E, Lu J, Gorret N, Guillouet SE, Sinskey AJ. Isopropanol production with engineered Cupriavidus necator as bioproduction platform. Appl Microbiol Biotechnol. 2014;98:4277-90.

9. Jillian M, Estelle G, Eric L, SA J, Nathalie G, Guillouet SE. Over expression of GroESL in Cupriavidus necator for heterotrophic and autotrophic isopropanol production. Metab Eng. 2017;42:74-84.

10. Chen JS, Colon B, Dusel B, Ziesack M, C Way J, Torella JP. Production of fatty acids in Ralstonia eutropha $\mathrm{H} 16$ by engineering beta-oxidation and carbon storage. PeerJ. 2015;3:e1468.

11. Krieg T, Sydow A, Faust S, Huth I, Holtmann D. $\mathrm{CO}_{2}$ to terpenes: autotrophic and electroautotrophic alpha-humulene production with Cupriavidus necator. Angewandte Chemie-International Edition. 2018;57:1879-82.

12. Barnard GC, Henderson GE, Srinivasan S, Gerngross TU. High level recombinant protein expression in Ralstonia eutropha using T7 RNA polymerase based amplification. Protein Expr Purif. 2004;38:264-71.

13. Fukui T, Ohsawa K, Mifune J, Orita I, Nakamura S. Evaluation of promoters for gene expression in polyhydroxyalkanoate-producing Cupriavidus necator H16. Appl Microbiol Biotechnol. 2011;89:1527-236.

14. Delamarre SC, Batt CA. Comparative study of promoters for the production of polyhydroxyalkanoates in recombinant strains of Wautersia eutropha. Appl Microbiol Biotechnol. 2006;71:668-79.

15. Sydow A, Pannek A, Krieg T, Huth I, Guillouet SE, Holtmann D. Expanding the genetic tool box for Cupriavidus necator by a stabilized L-rhamnose inducible plasmid system. J Biotechnol. 2017;263:1-10.

16. Li H, Liao JC. A synthetic anhydrotetracycline-controllable gene expression system in Ralstonia eutropha H16. ACS Synth Biol. 2015;4:101-6.

17. Simon R, Priefer U, Puher A. A broad host range mobilization system for in vivo genetic engineering transposon mutagenesis in gram negative bacteria. Nat Biotechnol. 1983:1:784-91.

18. Xiong B, Li Z, Liu L, Zhao D, Zhang X, Bi C. Genome editing of Ralstonia eutropha using an electroporation-based CRISPR-Cas9 technique. Biotechnol Biofuels. 2018;11:172.

19. Antoine R, Locht C. Isolation and molecular characterization of a novel broad-host-range plasmid from Bordetella bronchiseptica with sequence similarities to plasmids from gram-positive organisms. Mol Microbiol. 1992;6: 1799-85.

20. Quan J, Tian J. Circular polymerase extension cloning for high-throughput cloning of complex and combinatorial DNA libraries. Nature Protocol. 2011; 6:242-51.

21. Engler C, Gruetzner R, Kandzia R, Marillonnet S. Golden gate shuffling: a one-pot DNA shuffling method based on type lls restriction enzymes. PLoS One. 2009:4:e5553.

22. Gibson DG, Young L, Chuang R-Y, Venter JC, Hutchison CA, Smith HO Enzymatic assembly of DNA molecules up to several hundred kilobases. Nat Methods. 2009;6:343-5.

23. Hillson NJ, Rosengarten RD, Keasling JD. j5 DNA assembly design automation software. ACS Synth Biol. 2012;1:14-21.

\section{Publisher's Note}

Springer Nature remains neutral with regard to jurisdictional claims in published maps and institutional affiliations.

Ready to submit your research? Choose BMC and benefit from:

- fast, convenient online submission

- thorough peer review by experienced researchers in your field

- rapid publication on acceptance

- support for research data, including large and complex data types

- gold Open Access which fosters wider collaboration and increased citations

- maximum visibility for your research: over $100 \mathrm{M}$ website views per year

At BMC, research is always in progress.

Learn more biomedcentral.com/submissions 